\title{
Penetapan Instruktur Diklat Menggunakan Metode Clustering K-Means Dan Topsis Pada PT PLN (Persero) Udiklat Jakarta
}

\author{
Nurul Dyah Budiana ${ }^{1}$; Riki Ruli A. Siregar ${ }^{2}$; Meilia Nur Indah Susanti ${ }^{3}$ \\ 1, 2, ${ }^{3}$ Departemen Informatika Sekolah Tinggi Teknik PLN \\ ${ }^{1}$ nurul1431081@sttpln.ac.id
}

\begin{abstract}
Instructor is the main aspect that exists in the implementation of the training. The increasing number of instructors and the need for training is also increasing every year there is no system that can help the process of determining quickly and precisely. In need of a method that can classify the instructor data in accordance with the title of training materials and can be assigned instructor each of the training materials and do not ignore aspects of assessment of the instructor. In this study data mining techniques are used to help recommend instructors for each subject matter of the training based on the cluster data group approach. So it can be used in determining the instructor's assignment per training materials in the future. K-Means clustering method is used to group data into clusters by looking at the centroid value that has been determined. And the Topsis method is used to assign one instructor's name through the rankings of preference values. In this research CRISP-DM method is used as software engineering method system work done in sequence or linearly. In the testing process has been generated if the manual data and data processing if the application system is the same. This application to facilitate the Supervisor and Learning Development staff in setting instructors per training materials.
\end{abstract}

Keywords: Data mining, Clustering K-Means, Topsis, Determination of instructor per material

\begin{abstract}
ABSTRAK
Instruktur merupakan aspek utama yang ada dalam pelaksanaan diklat. Jumlah instruktur yang makin banyak dan kebutuhan akan diklat juga semakin bertambah tiap tahunnya, belum terdapat suatu sistem yang dapat membantu proses penetapan dengan cepat dan tepat. Di perlukan sebuah metode yang dapat mengelompokkan data instruktur sesuai dengan judul materi diklat dan dapat ditetapkan instruktur tiap materi diklat, serta tidak mengabaikan aspek-aspek penilaian instruktur. Dalam penelitian ini, Teknik data mining digunakan untuk membantu merekomendasikan instruktur tiap judul materi diklat berdasarkan pendekatan kelompok data kluster. Sehingga selanjutnya dapat digunakan dalam menentukan penetapan instruktur per materi diklat dimasa yang akan datang. Metode clustering K-Means digunakan untuk mengelompokkan data kedalam kluster dengan melihat nilai centroid yang sudah ditentukan. Dan metode Topsis digunakan untuk menetapkan satu nama instruktur melalui perangkingan nilai hasil preferensi. Pada penelitian ini metode CRISP-DM digunakan sebagai metode rekayasa perangkat lunaknya, pengerjaan sistem dilakukan secara berurutan atau secara linier. Pada proses pengujian telah dihasilkan jika data manual dan data hasil olah aplikasi sistem adalah sama. Aplikasi ini dapat mempermudah Supervisor dan staff Pengembangan Pembelajaran dalam menetapkan instruktur per materi diklat.
\end{abstract}

Kata kunci: Data mining, Clustering, K-Means, Topsis, Penetapan instruktur per materi 


\section{PENDAHULUAN}

Untuk menentukan instruktur per materi terdapat indikator-indikator yang dipertimbangkan dan telah ditetapkan oleh PUSDIKLAT, yaitu level grade, penguasaan materi, kompetensi instruktur dan transportasi yang mempunyai bobot-bobot penilaian tersendiri. Bobot-bobot tersebut yang digunakan Supervisor Pengembangan Pembelajaran dalam menilai setiap instruktur yang akan ditunjuk untuk menjadi instruktur diklat sesuai dengan materi yang telah ditentukan. Untuk mendapatkan hasil penentuan instruktur per judul materi diklat, pada penelitian ini dengan korelasi kasus penetapan instruktur materi diklat dengan menggunakan metode clustering K-Means dan metode SPK Topsis. K-means merupakan salah satu algoritma clustering. Tujuan algoritma ini yaitu untuk membagi data menjadi beberapa kelompok. Algoritma ini menerima masukan berupa data tanpa label kelas [1][2][3]. Metode $K$-Means digunakan untuk mengelompokkan instruktur berdasarkan materi diklat. Untuk menetapkan satu nama instruktur digunakan metode Technique for Order Preference by Similarity to Ideal Solution (TOPSIS) [4][5]. Metode ini banyak digunakan untuk menyelesaikan pengambilan keputusan secara praktis yang memiliki konsep dimana alternatif yang terpilih merupakan alternatif terpilih terbaik yang memiliki jarak terpendek dari solusi ideal positif dan jarak terjauh dari solusi ideal negatif. Penelitian K-Means cluster untuk pengelompkkan provinsi berdasarkan produksi padi, jagung, kedelai, dan kacang hijau tahun 2009. Dari penelitian yaitu mengelompokkan 33 provinsi kedalam tiga klaster dengan parameter penilaian dilihat dari hasil produksi padi, jagung, kedelai, dan kacang hijaudari tiap-tiap provinsi. Klaster 1 dengan prosentase 78,79\%, klister 2 dengan prosentase 12,12\%, klaster 3 dengan prosentase 9,09\% [3] . Analisa dan pemanfaatan algoritma k-means clustering pada data nilai siswa sebagai penentuan penerima beasiswa, algoritma k-means dapat melakukan pengelompokan dokumen dalam jumlah yang banyak untuk mengelompokkan data siswa kedalam kluster berdasarkan nilai siswa. Akan tetapi belum efisien dalam mengelompokan dokumen secara tepat. Penentuan centroid pada tahap awal algoritma k-means sangat berpengaruh pada hasil cluster seperti pada hasil pengujian yang dilakukan dengan menggunakan 100 record dengan centroid yang berbeda menghasilkan hasil cluster yang berbeda juga. Dari penelitian yang dilakukan k-means hanya dapat mengelompokkan data belum bisa memilih data secara tepat [6][7].

\section{METODE}

\subsection{Clustering K-Means}

K-Means digunakan dalam mengkluster data instruktur berdasarkan judul diklat. Data instruktur akan dikelompokkan ke masing-masing kluster yang telah ditentukan jumlahnya. Dengan menggunakan rumus [1]:

$$
\begin{aligned}
& \qquad d_{i j}=\sqrt{\sum_{k=1}^{p}\left\{x_{i k}-x_{j k}\right\}^{2}} \\
& \text { dimana: } \\
& \begin{array}{l}
d_{i j}=\text { Jarak objek antara objek i dan } \mathrm{j} \\
\mathrm{P} \quad=\text { Dimensi data } \\
X_{i k}=\text { Koordinat dari obyek i pada dimensi k } \\
X_{j k}=\text { Koordinat dari obyek j pada dimensi k }
\end{array}
\end{aligned}
$$


Tabel 1. Data Set Instruktur

\begin{tabular}{|c|l|l|l|l|l|}
\hline \multicolumn{2}{|c|}{ NAMA INSTRUKTUR } & $\begin{array}{c}\text { LEVEL } \\
\text { GRADE }\end{array}$ & $\begin{array}{c}\text { TRANSPOR } \\
\text { TASI }\end{array}$ & $\begin{array}{l}\text { PENGUASAAN } \\
\text { MATERI }\end{array}$ & $\begin{array}{l}\text { KOMPETENSI } \\
\text { KFINSTRUKT } \\
\text { URAN }\end{array}$ \\
\hline 1 & $\begin{array}{l}\text { WINAYU } \\
\text { SISWANTO }\end{array}$ & 6 & 3 & 2 & 1 \\
\hline 2 & SUMARDIONO & 3 & 3 & 3 & 3 \\
\hline 3 & ZAIDEL HAMDI & 6 & 3 & 2 & 3 \\
\hline 4 & $\begin{array}{l}\text { SRI AUKMANASARI } \\
\text { BUDIASIH }\end{array}$ & 5 & 3 & 2 & 1 \\
\hline 5 & TRI RAHAYU & 5 & 2 & 2 & 1 \\
\hline 6 & $\begin{array}{l}\text { REZA } \\
\text { HARDIANSYAH }\end{array}$ & 2 & 3 & 2 & 1 \\
\hline 7 & TITIEK TJAHYA & 5 & 3 & 4 & 1 \\
\hline 8 & GIOVANY & 3 & 3 & 4 & 1 \\
\hline 9 & $\begin{array}{l}\text { YEZIE DUI } \\
\text { GUMAY }\end{array}$ & 2 & 3 & 2 & 1 \\
\hline 10 & $\begin{array}{l}\text { MUKTAR } \\
\text { HENDRA }\end{array}$ & 2 & 3 & 2 & 1 \\
\hline
\end{tabular}

Langkah awal dari K-Means yaitu dengan menentukan jumlah kelompok yang ingin akan dicari. Sebagai contoh akan ditentukan 2 judul materi pembelajaran yaitu P2TL UNTUK TIM P2TL PEGAWAI PT PLN (PERSERO) TINGKAT: PELAKSANA OPERASI dan TEKNIK MENGAJAR EFEKTIF. Dengan penentuan centroid sesuai dengan kebutuhan Udiklat Jakarta.

a) C1 untuk materi P2TL UNTUK TIM P2TL PEGAWAI PT PLN (PERSERO) TINGKAT: PELAKSANA OPERASI dengan centroid awal sesuai kebutuhan
$\mathrm{C} 1=$ 6

3
$2 \quad 1$

b) C2 untuk materi TEKNIK MENGAJAR EFEKTIF dengan centroid awal yang ditetukan sesuai kebutuhan $\mathrm{C} 2=\begin{array}{llll}6 & 3 & 2 & 3\end{array}$

Menghitung jarak obyek pusat cluster dengan centroid dari data yang ada di masing-masing kelompok:

\section{Iterasi 1}

$$
\begin{aligned}
\mathrm{C} 1 & \\
\mathrm{C} 11 & =\sqrt{ }(6-6)^{2}+(3-3)^{2}+(2-2)^{2}+(1-1)^{2} \\
& =\sqrt{0}+0+0+0 \\
& =\sqrt{ } 0 \\
& =0 \\
\mathrm{C} 12 & =\sqrt{ }(3-6)^{2}+(3-3)^{2}+(3-2)^{2}+(3-1)^{2} \\
& =\sqrt{ }(-3)^{2}+0+1^{2}+2^{2} \\
& =\sqrt{9}+1+4 \\
& =\sqrt{14} \\
& =3,741 \\
\mathrm{C} 13 & =\sqrt{ }(6-6)^{2}+(3-3)^{2}+(2-2)^{2}+(3-1)^{2} \\
& =\sqrt{ } 0+0+0+2^{2} \\
& =\sqrt{4} \\
& =2
\end{aligned}
$$




$$
\begin{aligned}
& \mathrm{C} 14=\sqrt{(5-6)^{2}}+(3-3)^{2}+(2-2)^{2}+(1-1)^{2} \\
& =\sqrt{ }(-1)^{2}+0+0+0 \\
& =\sqrt{1} \\
& =1 \\
& \mathrm{C} 15=\sqrt{(5-6)^{2}+(2-3)^{2}+(2-2)^{2}+(1-1)^{2}} \\
& =\sqrt{(-1)^{2}}+(-1)^{2}+0+0 \\
& =\sqrt{1}+1 \\
& =\sqrt{2} \\
& =1.414
\end{aligned}
$$

Dan seterusnya,

\section{C2}

$$
\begin{aligned}
& \mathrm{C} 21=\sqrt{(6-6)^{2}}+(3-3)^{2}+(2-2)^{2}+(1-3)^{2} \\
& =\sqrt{0}+0+0+(-2)^{2} \\
& =\sqrt{4} \\
& =2 \\
& \mathrm{C} 22=\sqrt{(3-6)^{2}}+(3-3)^{2}+(3-2)^{2}+(3-3)^{2} \\
& =\sqrt{(-3)^{2}+0+1^{2}+0} \\
& =\sqrt{9}+1 \\
& =\sqrt{ } 10 \\
& =3,162 \\
& C 23=\sqrt{(6-6)^{2}+(3-3)^{2}+(2-2)^{2}+(3-3)^{2}} \\
& =\sqrt{ } 0+0+0+0 \\
& =0 \\
& \mathrm{C} 24=\sqrt{(5-6)^{2}}+(3-3)^{2}+(2-2)^{2}+(1-3)^{2} \\
& =\sqrt{(-1)^{2}+0+0+(-2)^{2}} \\
& =\sqrt{1}+0+0+4 \\
& =\sqrt{5} \\
& =2,236 \\
& \mathrm{C} 25=\sqrt{(5-6)^{2}+(2-3)^{2}+(2-2)^{2}+(1-3)^{2}} \\
& =\sqrt{(-1)^{2}}+(-1)^{2}+0+(-2)^{2} \\
& =\sqrt{1}+1+0+4 \\
& =\sqrt{6} \\
& =2,449
\end{aligned}
$$

Dan seterusnya,

Kelompokkan hasil hitungan berdasarkan kedekatan centroid, hingga menghasilkan pengelompokkan hasil cluster seperti berikut:

Tabel 2. Hasil Pengelompokan Kluster

\begin{tabular}{|c|c|c|c|}
\hline NO & iterasi2 & iterasi3 & Status \\
\hline 1 & $\mathrm{C} 1$ & $\mathrm{C} 1$ & Sesuai \\
\hline 2 & $\mathrm{C} 2$ & $\mathrm{C} 2$ & Sesuai \\
\hline 3 & $\mathrm{C} 2$ & $\mathrm{C} 2$ & Sesuai \\
\hline 4 & $\mathrm{C} 1$ & $\mathrm{C} 1$ & Sesuai \\
\hline 5 & $\mathrm{C} 1$ & $\mathrm{C} 1$ & Sesuai \\
\hline 6 & $\mathrm{C} 1$ & $\mathrm{C} 1$ & Sesuai \\
\hline 7 & $\mathrm{C} 1$ & $\mathrm{C} 1$ & Sesuai \\
\hline
\end{tabular}




\begin{tabular}{|c|c|c|c|}
\hline NO & iterasi2 & iterasi3 & Status \\
\hline 8 & $\mathrm{C} 1$ & $\mathrm{C} 1$ & Sesuai \\
\hline 9 & $\mathrm{C} 1$ & $\mathrm{C} 1$ & Sesuai \\
\hline 10 & $\mathrm{C} 1$ & $\mathrm{C} 1$ & Sesuai \\
\hline
\end{tabular}

Hasil iterasi kluster K-Means akan berhenti jika data hasil pengelompokkan kluster sudah sesuai antara iterasi sekarang dengan iterasi baru.

\subsection{Topsis (Technique for Order Preference by Similarity to Ideal Solution)}

Topsis digunakan dalam pengambil keputusan untuk penetapan instruktur yang sesuai dengan judul materi diklat berdasarkan perangkingan yang dilakukan oleh perhitungan Topsis [4]. Topsis memiliki konsep dimana alternatif yang terpilih merupakan alternatif terbaik yang memiliki jarak terpendek dari solusi ideal negatif. Semakin banyaknya faktor yang harus dipertimbangkan dalam proses pengambilan keputusan, maka makin relatif sulit juga untuk mengambil keputusan terhadap suatu permasalahan.

Pada penelitian ini, topsis menghitung perangkingan instruktur berdasarkan hasil clustering oleh KMeans berdasarkan masing-masing materi yang ditentukan. Hasil cluster C2 K-Means untuk judul diklat TEKNIK MENGAJAR EFEKTIF diolah kedalam proses Topsis. Mengkonversi data analisa dari k-Means kedalam bentuk perhitungan topsis.

Tabel 3. Data Hasil Rekomendasi

\begin{tabular}{|c|l|c|c|c|c|c|}
\hline NO & \multicolumn{1}{|c|}{ NAMA } & K1 & K2 & K3 & K4 & \\
\hline 2 & SUMARDIONO & 2 & 3 & 3 & 3 & data1 \\
\hline 3 & ZAIDEL HAMDI & 6 & 3 & 2 & 3 & \\
\hline 14 & RAMLI RAJULANG & 2 & 3 & 1 & 3 & data3 \\
\hline 20 & LILIES HENI & 4 & 3 & 2 & 3 & data4 \\
\hline 21 & RANUNES MANIDASE & 2 & 2 & 1 & 3 & data5 \\
\hline
\end{tabular}

\section{Menghitung matriks yang ternormalisasi}

$$
\begin{aligned}
|\mathrm{x} 1| & =\sqrt{(2)^{2}}+(6)^{2}+(2)^{2}+(4)^{2}+(3)^{2}+\cdots+(3)^{2} \\
& =\sqrt{104} \\
& =10,198 \\
\mathrm{R} 11 & =\frac{3}{10,198} \\
& =0,196 \\
\mathrm{R} 21 & =\frac{6}{10,198} \\
& =0,588 \\
\mathrm{R} 31 & =\frac{3}{10,198} \\
& =0,169 \\
\mathrm{R} 41 & =\frac{5}{10,198} \\
& =0,392
\end{aligned}
$$




$$
\begin{aligned}
\mathrm{R} 51 & =\frac{3}{10,198} \\
& =0,169
\end{aligned}
$$

Dan seterusnya,

$$
\begin{aligned}
& |\mathrm{x} 2|=\sqrt{(3)^{2}}+(3)^{2}+(3)^{2}+(3)^{2}+(2)^{2}+\cdots+(1)^{2} \\
= & \sqrt{90} \\
= & 9,486 \\
\mathrm{R} 12= & \frac{3}{9,486} \\
= & 0,316 \\
\mathrm{R} 22= & \frac{3}{9,486} \\
= & 0,316 \\
\mathrm{R} 32= & \frac{3}{9,486} \\
= & 0,316 \\
\mathrm{R} 42= & \frac{3}{9,486} \\
= & 0,316 \\
\mathrm{R} 52= & \frac{2}{9,486} \\
= & 0,210
\end{aligned}
$$

Dan seterusnya,

\section{Normalisasi terbobot}

Bobot $\mathrm{W}=0,3$

\section{$0,25 \quad 0,25 \quad 0,2$}

Tabel 4. Pembobotan Topsis

\begin{tabular}{|l|l|l|l|}
\hline 0,232 & 0,316 & 0,341 & 0,303 \\
\hline 0,464 & 0,316 & 0,227 & 0,303 \\
\hline 0,232 & 0,316 & 0,113 & 0,303 \\
\hline 0,386 & 0,316 & 0,227 & 0,303 \\
\hline 0,232 & 0,210 & 0,113 & 0,303 \\
\hline
\end{tabular}

Dst,

$$
\begin{aligned}
\mathrm{Y} 11 & =0,3 \times 0,232=0,069 \\
\mathrm{Y} 12 & =0,25 \times 0,316=0,079 \\
\mathrm{Y} 13 & =0,25 \times 0,341=0,085 \\
\mathrm{Y} 14 & =0,2 \times 0,303=0,060 \\
\mathrm{Y} 21 & =0,3 \times 0,464=0,139 \\
\mathrm{Y} 22 & =0,25 \times 0,316=0,079 \\
\mathrm{Y} 23 & =0,25 \times 0,227=0,056 \\
\mathrm{Y} 24 & =0,2 \times 0,303=0,060
\end{aligned}
$$

Hasil dari normalisasi terbobot dimasukkan kedalam bentuk matriks seperti berikut:

\begin{tabular}{|l|l|l|l|}
\hline 0.069 & 0.079 & 0.085 & 0.060 \\
\hline 0.139 & 0.079 & 0.057 & 0.060 \\
\hline 0.069 & 0.079 & 0.028 & 0.060 \\
\hline 0.116 & 0.079 & 0.057 & 0.060 \\
\hline 0.069 & 0.052 & 0.028 & 0.060 \\
\hline
\end{tabular}




\section{Solusi ideal positif $(\mathrm{A}+)$}
$=0,139$
0,079
0,113
0,060

Solusi ideal negative (A-)
$=0,046$
0,026
0,028
0,040

1. Jarak alternatif terbobot dengan solusi ideal positif

Rumus pada indeks ()

$$
\begin{aligned}
\mathrm{D} 1+ & =\sqrt{ }(0,069-0,139)^{2}+(0,079-0,079)^{2}+(0,085-0,113)^{2}+(0,060-0,060)^{2} \\
& =0,075 \\
\mathrm{D} 2+ & =\sqrt{ }(0,139-0,139)^{2}+(0,079-0,079)^{2}+(0,056-0,113)^{2}+(0,060-0,060)^{2} \\
& =0,056
\end{aligned}
$$

Dan seterusnya,

2. Jarak alternative dengan solusi ideal negatif

$$
\begin{aligned}
\text { D1- } & =\sqrt{ }(0,069-0,046)^{2}+(0,079-0,026)^{2}+(0,085-0,028)^{2}+(0,060-0,040)^{2} \\
& =0,083 \\
\text { D2- } & =\sqrt{ }(0,139-0,046)^{2}+(0,079-0,026)^{2}+(0,056-0,028)^{2}+(0,060-0,040)^{2} \\
& =0,112
\end{aligned}
$$

Dan seterusnya,

3. Nilai preferensi setiap alternative

$$
\begin{aligned}
\mathrm{V} 1 & =\frac{0,083}{0,083+0,075} \\
& =\frac{0,083}{0,158} \\
& =0,525 \\
\mathrm{~V} 2 & =\frac{0,112}{0,112+0,056} \\
& =\frac{0,112}{0,169} \\
& =0,663
\end{aligned}
$$

Sehingga terbentuk nilai preferensi seperti tabel dibawah ini:

Tabel 5. Hasil preferensi Topsis

\begin{tabular}{|c|r|r|r|r|l|}
\hline Data & D+ & D- & total D+ D- & V & HASIL \\
\hline 1 & 0,121 & 0,085 & 0,206 & 0,413 & bukan \\
\hline 2 & 0,056 & 0,160 & 0,217 & 0,737 & hasil \\
\hline 3 & 0,145 & 0,063 & 0,209 & 0,304 & bukan \\
\hline 4 & 0,081 & 0,108 & 0,190 & 0,569 & bukan \\
\hline 5 & 0,147 & 0,044 & 0,192 & 0,230 & Bukan \\
\hline
\end{tabular}

\section{HASIL DAN PEMBAHASAN}

Sebelum merekomendasikan instruktur per materi diklat, admin membuat rencana kegitan berdasarkan kebutuhan Udiklat berdasarkan empat kriteria penilaian instruktur yang nantinya dijadikan centroid dalam proses hitung K-Means. Sebagai berikut: 
Bulan

Judul Pembelajaran

Transportasi

Level Peserta

Kompetensi Instruktur

Penguasaan Materi

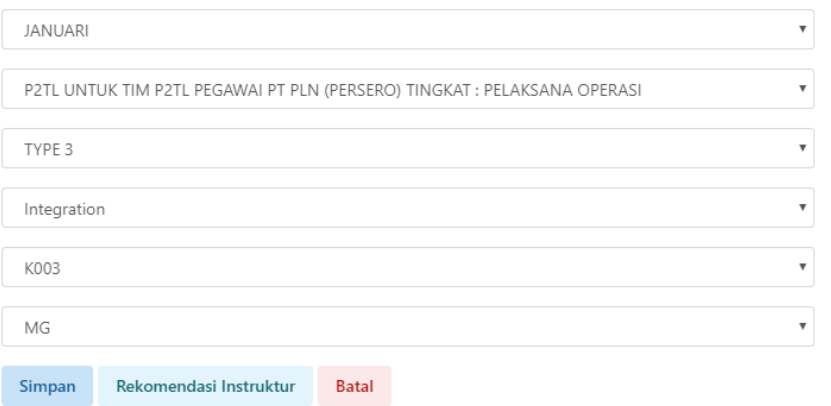

Gambar 2. Detail Rencana Kegiatan

\begin{tabular}{|c|c|c|c|c|c|c|c|c|}
\hline \multicolumn{6}{|c|}{ Rekomendasi Instruktur } & \multicolumn{2}{|c|}{ PERHITUNGAN MANUAL } & Simpan Rekome \\
\hline NIP & NAMA & LEVEL & STATUS & UNIT & KETERANGAN & GOLONGAN & & \\
\hline $6485014 \mathrm{~L}$ & WINAYU SISWANTO & $\begin{array}{l}\text { Belum } \\
\text { Ada }\end{array}$ & ITNPP & $\begin{array}{l}\text { PT PLN (Persero) } \\
\text { Distribusi Jakarta Raya }\end{array}$ & Aktif & C1 & Q Detail & 面 Hapus \\
\hline $5985004 \mathrm{D}$ & SUMARDIONO & Muda & ITNPP & $\begin{array}{l}\text { PT PLN (Persero) Kantor } \\
\text { Pusat }\end{array}$ & Aktif & $\mathrm{C} 2$ & Q Detail & in Hapus \\
\hline 6994159J & ZAIDEL HAMDI & $\begin{array}{l}\text { Belum } \\
\text { Ada }\end{array}$ & IT & $\begin{array}{l}\text { PT PLN (Persero) } \\
\text { Distribusi Jakarta Raya }\end{array}$ & Aktif & $\mathrm{C} 2$ & Q Detail & î Hapus \\
\hline $7496090 R$ & $\begin{array}{l}\text { SRI ATMI } \\
\text { SUKMANASARI } \\
\text { BUDIASIH }\end{array}$ & Muda & IT & $\begin{array}{l}\text { PT PLN (Persero) Kantor } \\
\text { Pusat }\end{array}$ & Aktif & C1 & Q Detail & 苗 Hapus \\
\hline $8003001 \mathrm{M}$ & TRI RAHAYU & $\begin{array}{l}\text { Belum } \\
\text { Ada }\end{array}$ & IT & $\begin{array}{l}\text { UIP JAWA BAGIAN } \\
\text { TIMUR \& BALI }\end{array}$ & Aktif & C1 & Q Detail & tin Hapus \\
\hline 5984021LMK & REZA HARDIANSYAH & $\begin{array}{l}\text { Belum } \\
\text { Ada }\end{array}$ & ITNPP & $\begin{array}{l}\text { PT PLN (Persero) Pusat } \\
\text { Pengatur Beban }\end{array}$ & Aktif & C1 & Q Detail & 面 Hapus \\
\hline $6186002 \mathrm{D}$ & TITIEK TJAHYA & $\begin{array}{l}\text { Belum } \\
\text { Ada }\end{array}$ & ITNPP & $\begin{array}{l}\text { PT PLN (Persero) Kantor } \\
\text { Pusat }\end{array}$ & Aktif & C1 & Q Detail & 苗 Hapus \\
\hline $7394161 \mathrm{M}$ & GIOVANY & Muda & IT & PT PLN (Persero) & Aktif & C1 & Q Detail & 酋 Hapus \\
\hline
\end{tabular}

Gambar 3. Hasil Rekomendasi Instruktur

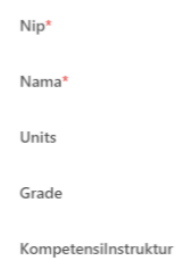

Penguasaan Materi
9295123XY

BELLA PUSPITA SUGARI

PT PLN (Persero) Distribusi Jakarta Raya

Optimation

INST

NS-Narasumber

Perhitungan Manual

Gambar 4. Hasil Penetapan Topsis 
Hasil rekomendasi instruktur per materi masuk ke proses Topsis untuk dapat diambil keputusan Instruktur per materi diklat. Penetapan dilakukan melalui perangkingan instruktur dengan atribut penilaian sesuai dengan K-means. Dan menghasilkan keputusan berikut:

Dilakukan uji keakurasian hasil aplikasi dengan studi kasus berikut:

Tabel 6. Tabel Pengujian Akurasi Aplikasi

\begin{tabular}{|l|l|l|l|l|l|l|l|l|l|l|}
\hline \multirow{2}{*}{ Atribut } & \multicolumn{10}{|c|}{ Hasil penetapan Aplikasi } \\
\cline { 2 - 13 } & R1 & H1 & R2 & H2 & R3 & H3 & R4 & H4 & R5 & H5 \\
\hline Transportasi & 3 & 3 & 3 & 3 & 2 & 3 & 3 & 3 & 3 & 3 \\
\hline Level Grade & 5 & 4 & 4 & 5 & 1 & 2 & 3 & 4 & 2 & 2 \\
\hline Kompetensi & 3 & 3 & 2 & 1 & 3 & 3 & 2 & 1 & 1 & 1 \\
\hline Penguasaan Materi & 3 & 4 & 2 & 3 & 3 & 2 & 4 & 4 & 2 & 3 \\
\hline
\end{tabular}

1. Akurasi kriteria transport

Tabel 7. Akurasi Transport

\begin{tabular}{|c|c|c|}
\hline & \multicolumn{2}{|c|}{ Nilai Sebenarnya (Rencana) } \\
\hline Nilai Prediksi & True & False \\
\hline True & 4 & 0 \\
\hline False & 1 & 0 \\
\hline
\end{tabular}

Akurasi $=\frac{4+0}{4+1+0 \pm 0}=\frac{4}{5}=0,8 \times 100 \%=80 \%$

\section{Akurasi kriteria level grade}

Tabel 8. Akurasi Level Grade

\begin{tabular}{|l|l|l|}
\hline & \multicolumn{2}{|c|}{ Nilai Sebenarnya (Rencana) } \\
\hline Nilai Prediksi & \multicolumn{1}{|c|}{ True } & False \\
\hline True & 1 & 0 \\
\hline False & 4 & 0 \\
\hline
\end{tabular}

Akurasi $=\frac{1+0}{1+4+0 \pm 0}=\frac{1}{5}=0,2 \times 100 \%=20 \%$

\section{Akurasi kriteria kompetensi instruktur}

Tabel 9. Akurasi Kompetensi Instruktur

\begin{tabular}{|c|c|c|}
\hline & \multicolumn{2}{|c|}{ Nilai Sebenarnya (Rencana) } \\
\hline Nilai Prediksi & True & False \\
\hline True & 3 & 0 \\
\hline False & 2 & 0 \\
\hline
\end{tabular}

Akurasi $=\frac{3+0}{3+2+0 \pm 0}=\frac{3}{5}=0,6 \times 100 \%=60 \%$ 


\section{Akurasi kriteria penguasaan materi}

Tabel 10. Akurasi Penguasaan Materi

\begin{tabular}{|l|l|l|}
\hline & \multicolumn{2}{|c|}{ Nilai Sebenarnya (Rencana) } \\
\hline Nilai Prediksi & \multicolumn{1}{|c|}{ True } & False \\
\hline True & 1 & 0 \\
\hline False & 4 & 0 \\
\hline
\end{tabular}

$$
\text { Akurasi }=\frac{1+0}{1+4+0 \pm 0}=\frac{1}{5}=0,2 \times 100 \%=20 \%
$$

Setelah dilakukan uji keakurasian dengan pengaplikasian metode precision recall pada hasil kesamaan antara rencana kegiatan dengan hasil yang didapat pada apllikasi, menyatakan bahwa nilai keakurasian tiap kriteria menunjukkan sebagai berikut; untuk kriteria transport sejumlah $80 \%$, kriteria level grade 20\%, kriteria kompetensi instruktur 60\%, kriteria penguasaan materi $20 \%$.

\section{KESIMPULAN DAN SARAN}

Berdasarkan hasil penelitian dan pembahasan yang telah dilakukan dapat diambil beberapa kesimpulan, antara lain:

1. Proses penetapan instruktur per materi diklat dilihat berdasarkan empat atribut utama yaitu level grade, transportasi, penguasaan materi, dan kompetensi instruktur yang dikelompokkan kedalam materi yang sesuai dan ditetapkan satu nama instruktur.

2. Dalam penelitian ini K-Means dapat mengelompokkan data instruktur ke dalam kluster berbeda berdasarkan judul materi yang telah ditentukan dengan centroid awal sesuai dengan kebutuhan.

3. Topsis dapat menentukan secara otomatis penentuan instruktur per materi diklat dilihat berdasarkan perangkingan yang didapat dari proses perhitungan Topsis dengan pembobotan 0,3 level grade, 0,25 transportasi, 0,25 penguasaan materi, 0,2 kompetensi instruktur. Dengan hasil nilai preferensi sebesar 0,848 .

4. Algoritma K-Means dan Topsis berdampak dalam mengelompokkan dan menetapkan instruktur sesuai dengan pendekatan kriteria masing-masing judul materi diklat yang direncanakan dengan nilai keakurasian tertinggi pada kriteria transport sebesar $80 \%$.

5. Aplikasi Penetapan Instruktur Per Materi Diklat Menggunakan Clustering K-Means dan Topsis Pada PT PLN (Persero) dapat membantu mengelola data-data terkait penetapan instruktur melalui menu monitoring.

\section{DAFTAR PUSTAKA}

[1] Barakbah, A. R., Fariza, A., \& Setiowati, Y. (2015). Optimization of Initial Centroid s for KMeans using Simulated Annealing. IES.

[2] Asroni, R. A. (2015). Penerapan Metode K-Means untuk Clustering Mahasiswa Berdasarkan Nilai Akademik Dengan Weka Interface Studi Kasus pada Jurusan Teknik Informatika UMM Magelang. JURNAL ILMIAH SEMESTA TEKNIKA VOL.18.

[3] E. Rivani, "Aplikasi K- Means Cluster Untuk Pengelompokkan Provinsi Berdasarkan Produksi Padi , Jagung, Kedelai, Dan Kacang Hijau Tahun 2009 Ukuran Similaritas," Mat Stat, vol. 10, no. 2, pp. 122-134, 2010. 
[4] Riandari, F., Hasugian, P. M., \& Taufik, I. (2017). Sistem Pendukung Keputusan Menggunakan Metode Topsis Dalam Memilih Kepala Departemen Pada Kantor Balai Wilayah Sungai Sumatera Ii Medan. Journal Of Informatic Pelita Nusantara.

[5] Jurnal, R. T. (2016). Penentuan Nasabah Penerima Reward Produk Gold dengan Metode Simple Additive Weighting (Saw) Studi Kasus: PT. Pinjam Indonesia. Petir, 9(1), 1-9.

[6] Muzakir, A. (2014). Analisa Dan Pemanfaatan Algoritma K-Means Clustering Pada Data Nilai Siswa Sebagai Penentuan Penerima Beasiswa. Snast.

[7] Siregar, R. R. A., Sinaga, F. A., \& Arianto, R. (2017). Aplikasi Penentuan Dosen Penguji Skripsi Menggunakan Metode TF-IDF dan Vector Space Model. Computatio: Journal of Computer Science and Information Systems, 1(2), 171-186.

[7] T. Nisa, R. Siregar, And W. Suliyanti, "Estimasi Daya Beban Listrik Pada Gardu Induk Cengkareng Dengan Menggunakan Metode Time Series Model Dekomposisi", Teknologia, Vol. 1, No. 2, Apr. 2019.

[8] Sangadji, I., \& Arvio, Y. (2018, March). Dynamic Segmentation Of Behavior Patterns Based On Quantity Value Movement Using Fuzzy Subtractive Clustering Method. In Journal of Physics: Conference Series (Vol. 974, No. 1, p. 012009). IOP Publishing.

[9] Siregar, R., Siregar, Z., \& Arianto, R. (2019). Klasifikasi Sentiment Analysis Pada Komentar Peserta Diklat Menggunakan Metode K-Nearest Neighbor. KILAT, 8(1). https://doi.org/10.33322/kilat.v8i1.421

[10] A. Prianty, R. Siregar, and R. Arianto, "Penanganan Gangguan Listrik Rumah Tangga Menggunakan Algoritma Greedy Untuk Penentuan Jarak Optimal”, Teknologia, vol. 2, no. 1, Aug. 2019.

[11] Siregar Rr, Putri Dr. Metode Support Vector Machine Pada Klasifikasi Audit Energi: Studi Kasus Gedung STT-PLN Jakarta. Jurnal Informatika Dan Komputasi. 2017 Mar 2;8(2):98104. 